\title{
A novel approach for calculating packed column height based on new correlation of mass transfer coefficient
}

\author{
Ahmad Rahbar-Kelishami ${ }^{1 *}$, Hossein Bahmanyar ${ }^{2}$, Zahra Hajamini ${ }^{1}$ \\ ${ }^{1}$ Iran University of Science \& Technology(IUST), Faculty of chemical engineering, Narmak, Tehran, Iran \\ ${ }^{2}$ University of Tehran (Iran) Engineering Collage, Chemical Engineering Faculty \\ "Corresponding author: e-mail: ahmadrahbar@iust.ac.ir
}

\begin{abstract}
The calculation of column's height plays an important role in packed columns precise design. This research is based on experimentally measurement of mass transfer coefficients in different heights of packed column to predict its height. The objective of presented work is to introduce a novel conceptual method to predict column height via new correlation for mass transfer coefficient. As the mass transfer coefficient is decreased with increase of column height, the HTU's are not constant figures along the column so this new approach is called increasing HTU's. The results of the proposed idea were compared with other correlations and the conventional method i.e. constant HTU's. Since the results are in very good agreement with experimental data comparing to conventional method, it seems this approach can be a turning point in design of all differential columns like packed columns. Making use of this method is suggested for design of differential columns.
\end{abstract}

Keywords: separation, liquid-liquid extraction, packed column, mass transfer, column design, diffusion.

\section{INTRODUCTION}

The liquid-liquid extraction is one of the most widely used unit operations in the process industry. The operation consists of separating one or several substances (solute) present in a liquid phase by the addition of another liquid phase in which these substances are transferred preferentially. The mass transfer process underlined the extraction often happens in counter-current type contactors. These contactors are generally classified into two groups, namely stage-wise and differential.

One of the major challenges in designing an industrial extraction column lies in the choice of the geometrical parameters specially height of the column. In order to design or scale up an extraction column, having a reasonable prediction of the mass transfer behaviors by a suitable mathematical model is essential. Furthermore, all previously proposed correlations for prediction of mass transfer coefficient in the extraction columns are independent of column height and would not provide reliable estimation when the mass transfer coefficient is a function of column height, In order to tackle with this deficiency, in a previous work the column height was introduced as a new parameter in the mass transfer coefficient equation which lead to a correlation with a high accuracy without which the data could not be fitted with an acceptable error ${ }^{1}$. The possibility of finding a similar correlation in counter-current mode (which shows dependency of mass transfer on height of column) is investigated in the present work. This experimental study confirms that a similar correlation for prediction of mass transfer coefficient can be obtained for counter-current operation with an acceptable average errors comparing to existing correlations. According to this new correlation, as the mass transfer coefficient is decreased with increase of column height, the HTU's are not constant figures along the column so this new approach is called increasing HTU's. With this new idea, increasing HTU's, the height of transfer unit (HTU), the height equivalent to a theoretical tray or plate, is not a constant value in the column. So this concept can introduce a novel approach in differential column design.
Therefore understanding of relevant column height and the mass transfer coefficients in these columns is of paramount importance for the precise design. Since one phase is dispersed in the other phase the explanation of mass transfer behavior in droplets is necessary for designing the extraction process.

Three important theoretical equations for prediction of the mass transfer coefficient are reviewed briefly. Also many other correlations have been proposed yet ${ }^{2}$. A similar job has been done on this extraction column for single drop system previously ${ }^{1}$. In this research we are trying to obtain an equivalent equation for counter-current conditions which considers the effect of height in correlation. Then a new mathematical method is applied to calculate height of packed column. The aim of this study is to introduce a novel conceptual method to predict column height via the new correlation for mass transfer coefficient. This method shows that the HTU is not a fixed value in column. This is a new and useful idea for more precise design of column.

\section{PREDICTION OF MASS TRANSFER COEFFICIENT}

The mass transfer coefficient of dispersed phase is one of the fundamental and essential parameters in the design of an extraction column. Several correlations have been proposed in past studies for calculation of mass transfer coefficient. The results of these studies have usually been interpreted in the light of three mechanisms of mass transfer inside drops. These three mechanisms are: i) considering the mass transfer rate of solute in a drop to be the molecular diffusion in a stagnant spherical drop $^{3}$, ii) laminar diffusion with circulation induced by relative motion of drop and continuous phase ${ }^{4}$, and iii) eddy diffusion between internal toroidal stream lines ${ }^{5}$. The governing equations are summarized in Table 1 . The small drops are found to be subject to the molecular diffusion rate control, but, large drops may exhibit Handlos-Baron behavior. The criteria of transition between different mechanisms of behavior are usually based on 
Table 1. Three proposed mechanisms of dispersed phase mass transfer coefficient

$$
\begin{aligned}
& \text { Molecular diffusion in stagnant drops (Newman equation) } \\
& K_{d}=-\left(\frac{d}{6 t}\right) \operatorname{Ln}\left[\left(\frac{6}{\pi^{2}}\right) \sum_{n=1}^{\infty}\left(\frac{1}{n^{2}}\right) \exp \left(-\frac{4 D_{d} \pi^{2} n^{2} t}{d^{2}}\right)\right] \quad \operatorname{Re} \leq 10
\end{aligned}
$$

Laminar diffusion with circulation induced by relative motion of drop and continuous phase

$$
K_{O d}=-\frac{d}{6 t} \ln \left[\frac{3}{8} \sum_{n=1}^{\infty} B_{n}^{2} \exp \left(-\frac{64 \lambda_{n} D_{d} t}{d^{2}}\right)\right] \quad 10 \leq \operatorname{Re} \leq 200
$$

Eddy diffusion between internal toroidal stream lines (Handlos and Baron equation)

$$
K_{\mathrm{Od}}=-\frac{d}{6 t} \ln \left[6 \sum_{n=1}^{\infty} B_{n}^{2} \exp \left(-\frac{\lambda_{n} V_{\mathrm{t}} t}{128 d(1+\kappa)}\right)\right] \quad 200 \leq \mathrm{Re}
$$

Reynolds or Weber or other factors which are found to be not very reliable.

Calderbank and Korchinski proposed an alternative approach involving the use of an enhanced molecular diffusivity, $\mathfrak{R D}$, (also referred to as effective diffusivity) in the equation of Kronig and Brink with the dimensionless enhancement factor ${ }^{6}, \mathfrak{R}=2.25$ :

$\mathrm{K}_{\mathrm{d}}=-\left(\frac{\mathrm{d}}{6 \mathrm{t}}\right) \operatorname{Ln}\left[1-\left\{1-\exp \left(-\frac{4 \pi^{2} \mathfrak{R D _ { \mathrm { d } } \mathrm { t }}}{\mathrm{d}^{2}}\right)\right\}^{1 / 2}\right]$

The circulation patterns and mixing intensity in oscillating drops are not well understood. The values of the mass transfer coefficients are experimentally similar to those predicted by the simple model of Handlos and Baron. This might be due to the internal circulation of drops. Photographic study of oscillating drops by Rose and Kintner shows that the toroidal circulation patterns postulated by Handlos and Baron deviate from reality. When the drop oscillates, the surface area changes with time ${ }^{7}$.

Johnson and Hamielec suggested the following equation with a new formula for determining $\mathfrak{R}^{\mathbf{8}}$ :

$\mathrm{K}_{\text {od }}=\left(-\frac{\mathrm{d}}{6 \mathrm{t}}\right) \ln \left[6 \sum_{\mathrm{n}=1}^{\infty} \mathrm{B}_{\mathrm{n}} \exp \left(\frac{-4 \lambda_{\mathrm{n}}^{2} \mathfrak{R} \mathrm{D}_{\mathrm{d}} \mathrm{t}}{\mathrm{d}^{2}}\right)\right]$

Since in their experiments which was the transfer of ethyl acetate into (vigorously circulating) water drops a rapid approach to equilibrium was observed, they considered only the first term of the series in the above equation and determined $\mathfrak{R}$ values:

$\Re=\frac{d V_{t}}{2048 D_{d}(1+\kappa)}$

Boyadzhiev et al. presented the following equation for calculating $\mathfrak{R}$ in equation (4) based on their own experimental data9:

$\mathfrak{R}=0.0125\left[\frac{\mathrm{Re}}{2(1+\kappa)}\right]$, for $\Rightarrow \frac{\mathrm{D}_{\mathrm{d}} \mathrm{t}}{\mathrm{d}^{2}}>10^{-2}$

Steiner also used equation (5) reduced to its first term of the summation series and evaluated $\mathfrak{R}$ values on the basis of data from nine sources. The equation proposed was ${ }^{\mathbf{1 0}}$ :

$\mathfrak{R}=1+0.177 \mathrm{Re}^{0.043} S c_{d}^{0.23}(1+\kappa\}^{-0.89} \quad$ for $\Rightarrow \quad \mathfrak{R}<10$

Temos et al presents the relation between eddy diffusivity and molecular diffusivity in a simple way ${ }^{\mathbf{1 1}}$ :

$\mathfrak{R}=1+0.44 \mathrm{D}_{\mathrm{E}} / \mathrm{D}_{\mathrm{d}}$

Where:

$D_{E}=3.29 \times 10^{-4}\left(\rho_{d} V_{i} d / \mu_{d}\right) \times\left[1-\exp \left(-3.29 \times 10^{-4}\left(\rho_{d} V_{i} d / \mu_{d}\right)\right)\right] \times\left(\frac{\mu_{d}}{\rho_{d}}\right)$
$\mathrm{V}_{\mathrm{i}}$ for $\mathrm{Re}>1$ is given by:

$\mathrm{V}_{\mathrm{i}}=\left\{1-\left[\frac{2+3 \kappa}{1+\left(\mu_{\mathrm{d}} \rho_{\mathrm{d}} / \mu_{\mathrm{c}} \rho_{\mathrm{c}}\right)^{0.5}}\right] \frac{1.45}{\mathrm{Re}^{0.5}}\right\} \mathrm{V}_{\mathrm{t}}$

The mass transfer coefficient is considered independent on height of column in all above mentioned correlations.

\section{EXPERIMENTAL}

\section{Set-up Description}

The packed column set up used in this study for continuous counter-current separation of acetic acid from dispersed phase was a $91 \mathrm{~mm} \times 1250 \mathrm{~mm}$ Pyrex glass column packed with two pieces of Penta-Pak TM PS-500M1 structured packing (Fig. 1). The total height of packing was $40 \mathrm{~cm}$ (Fig. 2). The packing was made of corrugated sheets in a cylindrical structure with a diameter equal to the internal diameter of column. The inclination of the corrugation is $45^{\circ}$.

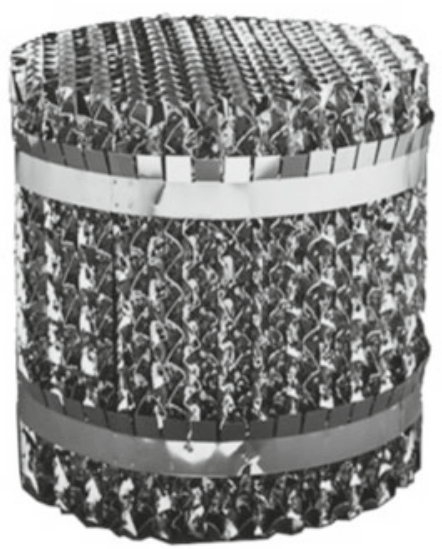

Figure 1. Applied structure packing

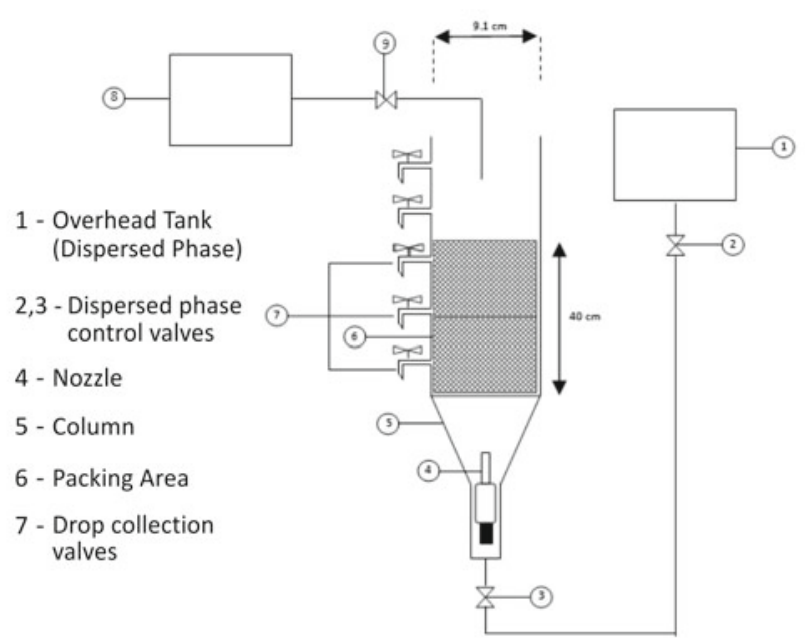

Figure 2. Schematic diagram of the apparatus

The experiment was carried out at room temperature under steady-state conditions. At the lower end of column, there is a discharge valve and glass entrance nozzle which can be used to connect to different nozzles for dispersed phase inlet. The dispersed phase enters through the bottom of column. The entrance nozzle of 
the dispersed phase has a valve which controls the speed of drops to the continuous phase. To collect the drops in different heights several plug type valves were used. The drops were collected and analyzed at the heights of $11,24.5,39 \mathrm{~cm}$ from the bottom of the column.

\section{Chemical Systems}

Two different dispersed phases was provided by adding 5 vol\% acetic acid to the saturated toluene and butyl acetate. Distilled water saturated with toluene and butyl acetate was used as the continuous phase. These two chemical systems, system 1: toluene-acetic acid-water (high interfacial tension) and system 2: $n$-butyl acetate-acetic acid-water (medium interfacial tension) were selected to increase the range of the interfacial tensions. The physical properties of these chemical systems are provided in Table 2.

Table 2. Physical properties of systems at $20^{\circ} \mathrm{C}$

\begin{tabular}{|l|c|c|}
\hline Physical property & $\begin{array}{c}\text { System 1 } \\
\text { T/A/W }\end{array}$ & $\begin{array}{c}\text { System 2 } \\
\text { B/A/W }\end{array}$ \\
\hline$\rho_{\mathrm{c}}\left[\mathrm{kg} / \mathrm{m}^{3}\right]$ & 1009.7 & 1010.2 \\
\hline$\rho_{\mathrm{d}}\left[\mathrm{kg} / \mathrm{m}^{3}\right]$ & 882.7 & 895.9 \\
\hline$\mu_{\mathrm{c}}[\mathrm{mPa} . \mathrm{s}]$ & 1.016 & 1.013 \\
\hline$\mu_{\mathrm{d}}[\mathrm{mPa} . \mathrm{s}]$ & 0.611 & 0.684 \\
\hline$\gamma[\mathrm{mN} / \mathrm{m}]$ & $27.5-30.1$ & $12.4-13.2$ \\
\hline$D_{\mathrm{d}}\left[\mathrm{m}^{2} / \mathrm{s}\right]$ & $2.92 \times 10^{-9}$ & $2.66 \times 10^{-9}$ \\
\hline
\end{tabular}

Calculation of experimental dispersed-phase mass transfer coefficient

Considering the mass balance for a single drop the following equation can be obtained:

$K_{d}=\left(-\frac{d}{6 t}\right) \ln (1-E)$

where:

$\mathrm{E}=\frac{\mathrm{c}_{0}-\mathrm{c}}{\mathrm{c}_{0}-\mathrm{c}^{*}}$

$\mathrm{c}_{\mathrm{o}}, \mathrm{c}, \mathrm{c}^{*}$ are solute concentration in primary drop (before contact), concentration in specific position and the concentration in equilibrium with continuous phase, respectively which is measured through collecting the drops and doing titration using normal NaoH.

In each experiment and for different heights of the column by measuring Acetic Acid concentration, mean diameter and terminal velocity of droplets and the contact time between two phases, the mass transfer coefficients are calculated considering equation (12).

In order to find a correlation for the effective diffusivity for the counter-current conditions, the experimental values of the mass transfer coefficients are used in the Newman equation. In practice the drops will experience different events during their passage through the column such as breakage, coalescence and so on. The effective diffusivity can consider all above mentioned events. The experimental values of the mass transfer coefficients obtained from equation 12 are used in Newman equation to find the effective diffusivity. The molecular diffusivity obtained from experimental data in the Newman equation would act as the effective diffusivity.

\section{CALCULATION OF COLUMN HEIGHT}

In all previously published works, the HTU is considered as a fixed value in a specified column ${ }^{12,13}$. There are also tables which give the values of HTU for a specific type of packing ${ }^{14}$. Although the variation of HTU has been confirmed by some people, no theoretical explanation has been proposed to support this finding. As it has been discussed ${ }^{\mathbf{1}}$, the mass transfer coefficient is intensively affected by height of packing in a single drop system. The present work aims to study the existence of similar trend for counter current condition. Such trend may happen due to the fact that by approaching the end of the column decreasing the solute concentration results in less mass transfer rate and less values for mass transfer coefficients. Thus, assumption of a constant mass transfer coefficient in calculating the height of column is not correct anymore. Indeed, with increasing the packing height while the mass transfer coefficient is decreasing, the equivalent height of column (theoretical plate) increases. The counter-current differential extractors such as packed columns are characterized by a continuous change in the concentration profile from top to bottom, rather than step changes. The flux of solute through the interface is related to the change of solute concentration across the section as follows ${ }^{15}$ :

$d N_{a}=-U_{d} d C_{d}=K_{d} a\left(C_{d}-C_{d}^{i}\right) d h$

Where $C_{d}$ is the concentration of the dispersed phase, $\mathrm{C}_{\mathrm{d}}{ }_{\mathrm{i}}$ is that at the interface and dh is the differential height.

In order to calculate the height of column, equation (14) was rearranged and integrated in the following form: $H=\frac{U_{d}}{K_{d} a} \int_{C_{d,}}^{C_{d, 0}} \frac{d C_{d}}{\left(C_{d}-C_{d}^{i}\right)}$

In that approach, as stated before, it is assumed that the mass transfer coefficient is constant and is not depended on the height of column. The total height of packed column needed can be established by the product of NTU and HTU.

Eq. (15) may be conveniently expressed as:

$H=H T U * N T U$

where NTU, termed the number of transfer units, is given by:

$N T U=\int_{C_{d l,}}^{C_{d, 0}} \frac{d C_{d}}{\left(C_{d}-C_{d}^{i}\right)}$

The HTU, the height of transfer unit is constant and given by:

$H T U=\frac{U_{d}}{K_{d} a}$

This is a simple method of representation which has been widely used as a method of design.

In the new approach proposed here, the mass transfer coefficient is a function of column height, thus Eq. (14) can be rewritten as:

$\int_{0}^{H} K_{d} d h=\frac{U_{d}}{a} N T U$

For a specific separation NTU is fixed and the integration calculation should be repeated for the number of transfer units.

In the first step to determine the first HTU, NTU is considered to be equal to 1 and the integral limits are defined as below: 
$\int_{H 0}^{H 1} K_{d} d h=\frac{U_{d}}{a} * 1$

$\mathrm{H}_{0}$ is very small and considered to be 0.001 to initiate the calculations.

As discussed before, the correlation of mass transfer coefficient applied here is ${ }^{2}$ :

$K_{d}=\frac{-d}{6 t} \ln \left(\frac{61}{\pi^{2}} \sum_{1}^{100} \frac{-}{i^{2}} \exp \left(\frac{-4 t i^{22} \pi D_{e f f}(h)}{d^{2}}\right)\right)$

Equation (20) can be solved to obtain $\mathrm{H}_{1}$. The first HTU, HTU1, is then obtained as:

$H T U 1=H 1-H 0$

To calculate HTU2 the following equation should be solved:

$\int_{H 1}^{H 2} K_{d} d h=\frac{U_{d}}{a} * 1$

HTU2 is then obtained as:

$H T U 2=H 2-H 1$

This approach is continued for the number of transfer units. The total required height is the summation of these HTU's.

Although other mathematical procedures can be applied to solve Eq. (19), the presented method is desirable as it is a very simple and apprehensible method. Moreover, the concept of different HTU's (in contrast to identical ones) can be readily expressed by this method.

\section{RESULTS AND DISCUSSIONS}

\section{Mass transfer coefficients}

The results of this experimental study show that the mass transfer coefficient is strongly affected by column height. The effect of column height on mass transfer coefficients is given in Figures 3 and 4. In these Figures effective diffusivity versus Reynolds number is presented in different heights of the column for two chemical systems. Figure 3 presents data for the first chemical system, toluene-acetic acid-water and the counterpart values for second chemical system, n-butyl acetate-acetic acid-water, are shown in Figure 4. As shown in these figures, the diffusivity of the dispersed phase increases by decreasing column height. This happens due to the fact that by approaching the end of the column the decrease in solute concentration results in less mass transfer driving force and smaller values for the mass transfer coefficients. Comparison of the effective diffusivities of

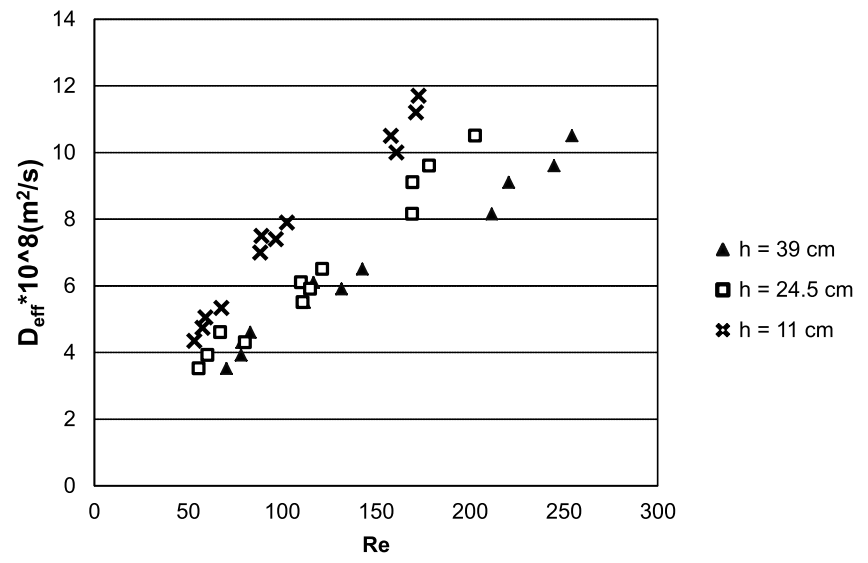

Figure 3. $D_{\text {eff }}$ versus Re in different heights of column, $T / \Omega / A$.

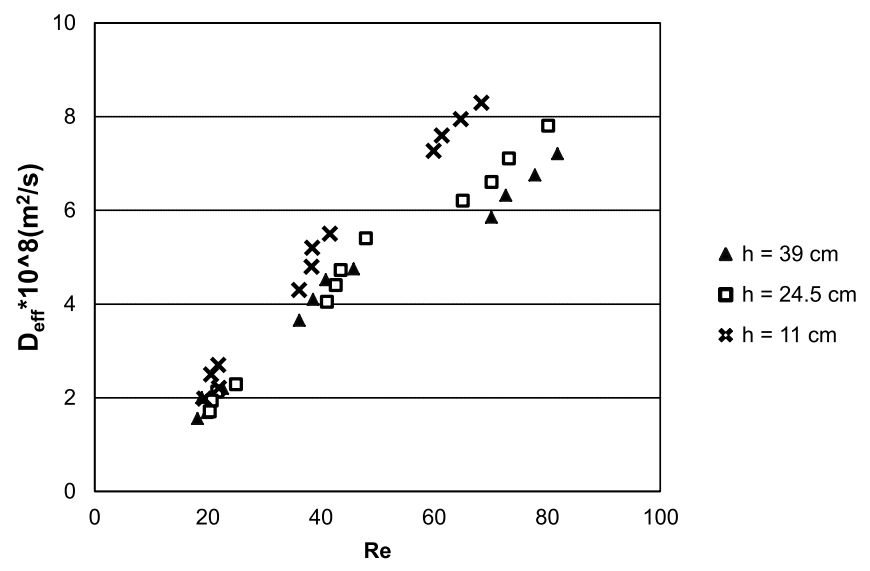

Figure 4. $D_{\text {eff }}$ versus Re in different heights of column, $B / \Omega / A$

two systems also shows that the second system, n-butyl acetate-acetic acid-water, has less values of $\mathrm{D}_{\text {eff }}$. This is due to lower interfacial tension in this system. It means that for a system with lower values of interfacial tension, the mass transfer coefficients are smaller because of less internal circulations of droplets.

Regression of the experimental data based on the diffusion concept discussed before leads to the following correlation.

$D_{\text {eff }}=2.18 * 10^{-9} * h^{-0.25} * \mathrm{Re}^{0.66}$

This correlation is similar to the one previously proposed for a single drop system ${ }^{\mathbf{1}}$.

The predictions of the proposed correlation are compared with the experimental data for the dispersed phase mass transfer coefficient in Figure 5. As the Figure shows, the suggested correlation can accurately predict the experimental data with an average error of $14 \%$.

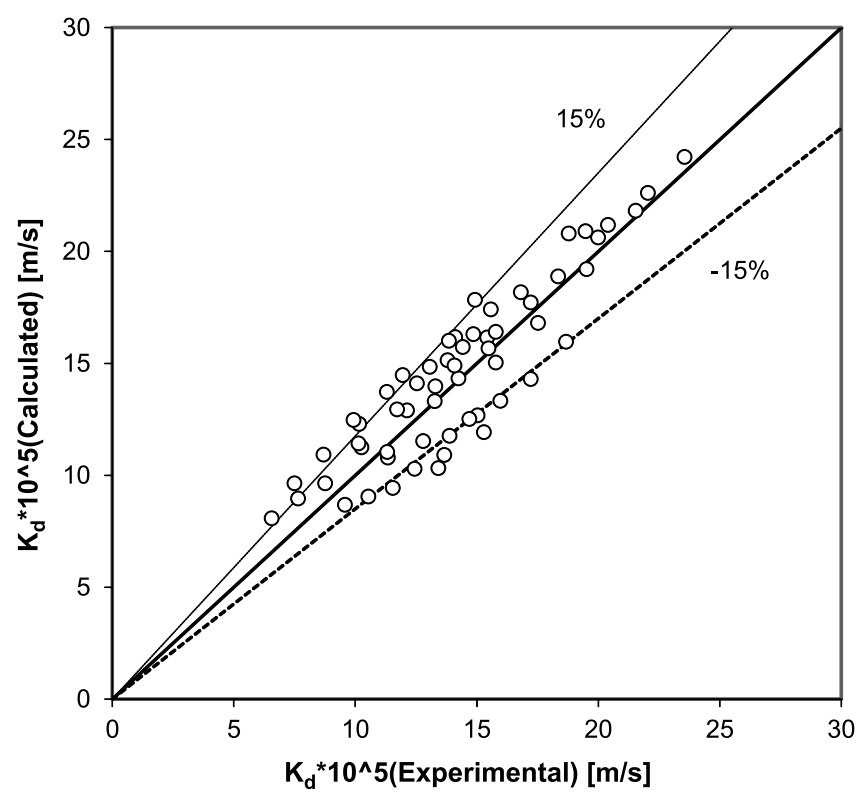

Figure 5. Comparison of experimental results with calculated values

\section{Height of Packed Column}

For our experimental study with a specific separation the explained mathematical procedure is applied. The required heights of packed column are derived for different conditions. 
The obtained HTU's using the proposed approach are presented in Tables 3-8. A large number of correlations for prediction of mass transfer coefficient are available in the literature ${ }^{6-10}$. Three major correlations were chosen for comparison to the correlation proposed here. As can be seen in the first row of Table 5, the

Table 3. Experimental and calculated height using selected equations, T/A/W, h $=11 \mathrm{~cm}$

\begin{tabular}{|c|c|c|c|c|c|c|c|c|c|c|}
\hline $\mathrm{C}_{\text {out }}$ & NTU & Experimental & \multicolumn{2}{|c|}{ Newman } & \multicolumn{2}{|c|}{ Kronig and Brink } & \multicolumn{2}{|c|}{ Handlos and Baron } & \multicolumn{2}{|c|}{ Present Work } \\
\hline [mole/lit] & & [m] & $\begin{array}{c}\text { Calculated } \\
{[\mathrm{m}]}\end{array}$ & Err. [\%] & $\begin{array}{c}\text { Calculated } \\
{[\mathrm{m}]}\end{array}$ & Err. [\%] & $\begin{array}{c}\text { Calculated } \\
{[\mathrm{m}]}\end{array}$ & Err. [\%] & $\begin{array}{c}\text { Calculated } \\
{[\mathrm{m}]}\end{array}$ & Err. [\%] \\
\hline 0.107 & 1.84 & 0.11 & 0.69 & 523.8 & 0.37 & 238.9 & 0.05 & 52.4 & 0.081 & 26.02 \\
\hline 0.102 & 1.89 & 0.11 & 0.67 & 509.5 & 0.37 & 232.2 & 0.04 & 59.3 & 0.084 & 23.86 \\
\hline 0.112 & 1.80 & 0.11 & 0.64 & 481.3 & 0.35 & 216.8 & 0.04 & 63.4 & 0.079 & 27.89 \\
\hline 0.116 & 1.76 & 0.11 & 0.61 & 452.0 & 0.33 & 201.4 & 0.04 & 67.5 & 0.078 & 28.89 \\
\hline 0.168 & 1.39 & 0.11 & 0.79 & 616.6 & 0.41 & 275.8 & 0.04 & 62.2 & 0.077 & 29.72 \\
\hline 0.171 & 1.37 & 0.11 & 0.76 & 589.9 & 0.40 & 262.5 & 0.04 & 65.4 & 0.076 & 31.24 \\
\hline 0.157 & 1.46 & 0.11 & 0.77 & 604.5 & 0.41 & 271.5 & 0.04 & 66.6 & 0.081 & 25.96 \\
\hline 0.170 & 1.38 & 0.11 & 0.74 & 570.9 & 0.39 & 253.7 & 0.03 & 69.1 & 0.076 & 30.94 \\
\hline 0.273 & 0.91 & 0.11 & 0.87 & 694.2 & 0.43 & 294.0 & 0.02 & 77.5 & 0.108 & 2.22 \\
\hline 0.287 & 0.85 & 0.11 & 0.86 & 677.3 & 0.43 & 286.8 & 0.02 & 79.3 & 0.101 & 7.74 \\
\hline 0.286 & 0.86 & 0.11 & 0.83 & 650.8 & 0.41 & 274.5 & 0.02 & 81.2 & 0.102 & 7.43 \\
\hline 0.302 & 0.81 & 0.11 & 0.80 & 626.3 & 0.40 & 261.5 & 0.02 & 82.7 & 0.099 & 10.02 \\
\hline \multicolumn{3}{|c|}{ Average Absolute Error } & & 583.1 & & 255.8 & & 68.9 & & 20.99 \\
\hline
\end{tabular}

Table 4. Experimental and calculated height using selected equations, $\mathrm{T} / \mathrm{A} / \mathrm{W}, \mathrm{h}=24.5 \mathrm{~cm}$

\begin{tabular}{|c|c|c|c|c|c|c|c|c|c|c|}
\hline $\mathrm{C}_{\text {out }}$ & NTU & Experimental & \multicolumn{2}{|c|}{ Newman } & \multicolumn{2}{|c|}{ Kronig and Brink } & \multicolumn{2}{|c|}{ Handlos and Baron } & \multicolumn{2}{|c|}{ Present Work } \\
\hline [mole/lit] & & [m] & $\begin{array}{c}\text { Calculated } \\
{[\mathrm{m}]}\end{array}$ & Err. [\%] & $\begin{array}{c}\text { Calculated } \\
{[\mathrm{m}]}\end{array}$ & Err. [\%] & $\begin{array}{c}\text { Calculated } \\
{[\mathrm{m}]}\end{array}$ & Err. [\%] & $\begin{array}{c}\text { Calculated } \\
{[\mathrm{m}]}\end{array}$ & Err. [\%] \\
\hline 0.025 & 3.28 & 0.245 & 1.56 & 538.4 & 0.86 & 251.6 & 0.11 & 54.0 & 0.142 & 41.92 \\
\hline 0.053 & 2.54 & 0.245 & 1.57 & 539.5 & 0.86 & 252.5 & 0.08 & 67.7 & 0.105 & 57.24 \\
\hline 0.036 & 2.93 & 0.245 & 1.43 & 484.5 & 0.79 & 222.1 & 0.08 & 68.5 & 0.148 & 39.79 \\
\hline 0.045 & 2.71 & 0.245 & 1.35 & 452.9 & 0.75 & 204.9 & 0.06 & 76.3 & 0.155 & 36.79 \\
\hline 0.084 & 2.09 & 0.245 & 1.85 & 654.0 & 1.00 & 307.7 & 0.08 & 68.6 & 0.203 & 17.34 \\
\hline 0.085 & 2.07 & 0.245 & 1.76 & 616.8 & 0.95 & 288.7 & 0.07 & 72.6 & 0.197 & 19.65 \\
\hline 0.089 & 2.02 & 0.245 & 1.78 & 627.0 & 0.96 & 293.2 & 0.07 & 72.6 & 0.192 & 21.68 \\
\hline 0.099 & 1.92 & 0.245 & 1.68 & 583.9 & 0.91 & 270.1 & 0.06 & 75.4 & 0.178 & 27.40 \\
\hline 0.189 & 1.27 & 0.245 & 2.05 & 735.7 & 1.05 & 329.3 & 0.04 & 82.7 & 0.228 & 7.11 \\
\hline 0.183 & 1.31 & 0.245 & 1.98 & 707.9 & 1.02 & 317.1 & 0.04 & 84.7 & 0.226 & 7.56 \\
\hline 0.195 & 1.24 & 0.245 & 1.84 & 652.6 & 0.95 & 289.2 & 0.03 & 86.4 & 0.214 & 12.83 \\
\hline 0.211 & 1.16 & 0.245 & 1.76 & 616.7 & 0.91 & 270.0 & 0.03 & 87.7 & 0.202 & 17.45 \\
\hline Average & E Erro & & & 600.8 & & 274.7 & & $\begin{array}{l}74.8 \\
\end{array}$ & & 25.56 \\
\hline
\end{tabular}

Table 5. Experimental and calculated height using selected equations, T/A/W, h $=39 \mathrm{~cm}$

\begin{tabular}{|c|c|c|c|c|c|c|c|c|c|c|}
\hline $\mathrm{C}_{\text {out }}$ & NTU & Experimental & \multicolumn{2}{|c|}{ Newman } & \multicolumn{2}{|c|}{ Kronig and Brink } & \multicolumn{2}{|c|}{ Handlos and Baron } & \multicolumn{2}{|c|}{ Present Work } \\
\hline [mole/lit] & & [m] & $\begin{array}{c}\text { Calculated } \\
{[\mathrm{m}]}\end{array}$ & Err. [\%] & $\begin{array}{c}\text { Calculated } \\
{[\mathrm{m}]}\end{array}$ & Err. [\%]] & $\begin{array}{c}\text { Calculated } \\
{[\mathrm{m}]}\end{array}$ & Err. [\%] & $\begin{array}{c}\text { Calculated } \\
{[\mathrm{m} / \mathrm{s}]}\end{array}$ & \begin{tabular}{|l} 
Err. \\
{$[\%]$}
\end{tabular} \\
\hline 0.014 & 3.89 & 0.39 & 2.83 & 627.2 & 1.56 & 299.8 & 0.14 & 64.4 & 0.308 & 21.08 \\
\hline 0.016 & 3.74 & 0.39 & 2.69 & 590.2 & 1.48 & 279.3 & 0.12 & 68.8 & 0.253 & 35.01 \\
\hline 0.023 & 3.40 & 0.39 & 2.47 & 533.6 & 1.36 & 248.4 & 0.11 & 72.6 & 0.255 & 34.54 \\
\hline 0.025 & 3.31 & 0.39 & 2.30 & 490.8 & 1.26 & 224.1 & 0.09 & 76.6 & 0.239 & 38.78 \\
\hline 0.059 & 2.44 & 0.39 & 2.94 & 654.0 & 1.61 & 312.0 & 0.10 & 73.4 & 0.269 & 31.11 \\
\hline 0.047 & 2.67 & 0.39 & 2.92 & 649.8 & 1.61 & 311.7 & 0.09 & 76.8 & 0.295 & 24.38 \\
\hline 0.066 & 2.33 & 0.39 & 2.74 & 605.0 & 1.50 & 285.7 & 0.09 & 77.6 & 0.269 & 30.90 \\
\hline 0.057 & 2.46 & 0.39 & 2.69 & 590.5 & 1.48 & 279.2 & 0.08 & 80.3 & 0.274 & 29.84 \\
\hline 0.162 & 1.43 & 0.39 & 3.26 & 737.2 & 1.69 & 334.1 & 0.06 & 85.1 & 0.336 & 13.95 \\
\hline 0.175 & 1.35 & 0.39 & 3.07 & 688.2 & 1.59 & 308.8 & 0.05 & 86.8 & 0.319 & 18.11 \\
\hline 0.169 & 1.39 & 0.39 & 3.00 & 671.2 & 1.57 & 301.7 & 0.05 & 88.0 & 0.322 & 17.41 \\
\hline 0.183 & 1.30 & 0.39 & 2.79 & 617.5 & 1.46 & 274.1 & 0.04 & 89.4 & 0.289 & 25.88 \\
\hline \multicolumn{4}{|c|}{ Average Absolute Error } & 621.3 & & 288.2 & & 78.3 & & 26.75 \\
\hline
\end{tabular}

Table 6. Experimental and calculated height using selected equations, B/A/W, h $=11 \mathrm{~cm}$

\begin{tabular}{|c|c|c|c|c|c|c|c|c|c|c|}
\hline $\mathrm{C}_{\text {out }}$ & NTU & Experimental & \multicolumn{2}{|c|}{ Newman } & \multicolumn{2}{|c|}{ Kronig and Brink } & \multicolumn{2}{|c|}{ Handlos and Baron } & \multicolumn{2}{|c|}{ Present Work } \\
\hline [mole/lit] & & [m] & $\begin{array}{c}\text { Calculated } \\
{[\mathrm{m}]}\end{array}$ & Err.[\%] & $\begin{array}{c}\text { Calculated } \\
{[\mathrm{m}]}\end{array}$ & Err. [\%] & $\begin{array}{c}\text { Calculated } \\
{[\mathrm{m}]}\end{array}$ & Err. [\%] & $\begin{array}{c}\text { Calculated } \\
{[\mathrm{m}]}\end{array}$ & Err. [\%] \\
\hline 0.016 & 3.73 & 0.11 & 0.61 & 455.2 & 0.33 & 199.8 & 0.05 & 53.9 & 0.082 & 25.49 \\
\hline 0.023 & 3.37 & 0.11 & 0.57 & 413.6 & 0.31 & 178.1 & 0.04 & 65 & 0.079 & 28.16 \\
\hline 0.046 & 2.68 & 0.11 & 0.49 & 346.4 & 0.27 & 143.7 & 0.03 & 72.8 & 0.067 & 39.17 \\
\hline 0.048 & 2.64 & 0.11 & 0.46 & 316.7 & 0.25 & 126.5 & 0.02 & 77.5 & 0.065 & 40.53 \\
\hline 0.059 & 2.43 & 0.11 & 0.8 & 624 & 0.44 & 296.5 & 0.04 & 68.1 & 0.113 & 3.11 \\
\hline 0.059 & 2.44 & 0.11 & 0.77 & 602.3 & 0.42 & 285.2 & 0.03 & 71.2 & 0.113 & 3.06 \\
\hline 0.071 & 2.25 & 0.11 & 0.72 & 556.2 & 0.4 & 259.8 & 0.03 & 74 & 0.105 & 4.91 \\
\hline 0.081 & 2.12 & 0.11 & 0.67 & 507.2 & 0.37 & 233.2 & 0.02 & 77.6 & 0.098 & 11.33 \\
\hline 0.108 & 1.83 & 0.11 & 0.88 & 703.2 & 0.47 & 322.9 & 0.03 & 71.3 & 0.127 & 15.82 \\
\hline 0.113 & 1.79 & 0.11 & 0.87 & 694.3 & 0.46 & 320.3 & 0.03 & 74.1 & 0.124 & 13.07 \\
\hline 0.117 & 1.75 & 0.11 & 0.85 & 673 & 0.45 & 309.5 & 0.03 & 76.8 & 0.123 & 11.57 \\
\hline 0.129 & 1.66 & 0.11 & 0.82 & 644.8 & 0.43 & 294.1 & 0.02 & 79.8 & 0.12 & 9.52 \\
\hline Average & & & & 544.7 & & 247.5 & & 71.8 & & 17.15 \\
\hline
\end{tabular}


Table 7. Experimental and calculated height using selected equations, B/A/W, h $=24.5 \mathrm{~cm}$

\begin{tabular}{|c|c|c|c|c|c|c|c|c|c|c|}
\hline $\mathrm{C}_{\text {out }}$ & NTU & Experimental & \multicolumn{2}{|c|}{ Newman } & \multicolumn{2}{|c|}{ Kronig and Brink } & \multicolumn{2}{|c|}{ Handlos and Baron } & \multicolumn{2}{|c|}{ Present Work } \\
\hline [mole/lit] & & {$[\mathrm{m}]$} & $\begin{array}{c}\text { Calculated } \\
{[\mathrm{m}]}\end{array}$ & Err. \% & $\begin{array}{c}\text { Calculated } \\
{[\mathrm{m}]}\end{array}$ & Err. [\%] & $\begin{array}{c}\text { Calculated } \\
{[\mathrm{m}]}\end{array}$ & Err. [\%] & $\begin{array}{c}\text { Calculated } \\
{[\mathrm{m}]}\end{array}$ & Err. [\%] \\
\hline 0.002 & 6.05 & 0.245 & 1.42 & 480.4 & 0.71 & 190.6 & 0.1 & 59.6 & 0.163 & 33.48 \\
\hline 0.002 & 6.05 & 0.245 & 1.36 & 455.2 & 0.67 & 175.3 & 0.08 & 67.7 & 0.168 & 31.46 \\
\hline 0.003 & 5.55 & 0.245 & 1.24 & 407.9 & 0.62 & 151.7 & 0.07 & 73 & 0.156 & 36.53 \\
\hline 0.005 & 4.85 & 0.245 & 1.15 & 367.5 & 0.57 & 134.3 & 0.05 & 79.1 & 0.146 & 40.48 \\
\hline 0.01 & 4.18 & 0.245 & 2.11 & 761.4 & 1.16 & 375.2 & 0.07 & 71.3 & 0.275 & 12.16 \\
\hline 0.013 & 3.97 & 0.245 & 1.92 & 683.9 & 1.06 & 331.9 & 0.06 & 75.9 & 0.252 & 3.05 \\
\hline 0.017 & 3.7 & 0.245 & 1.8 & 635 & 0.99 & 305.1 & 0.05 & 78.7 & 0.238 & 2.98 \\
\hline 0.02 & 3.5 & 0.245 & 1.68 & 586.7 & 0.93 & 278.3 & 0.05 & 81 & 0.223 & 9.06 \\
\hline 0.039 & 2.84 & 0.245 & 2.23 & 811.1 & 1.21 & 395.7 & 0.06 & 76 & 0.283 & 15.36 \\
\hline 0.042 & 2.78 & 0.245 & 2.11 & 761.7 & 1.15 & 370.1 & 0.05 & 79 & 0.273 & 11.24 \\
\hline 0.048 & 2.65 & 0.245 & 2 & 715.9 & 1.09 & 345.4 & 0.05 & 81.5 & 0.261 & 6.46 \\
\hline 0.05 & 2.6 & 0.245 & 1.92 & 684.9 & 1.05 & 329.1 & 0.04 & 83.8 & 0.257 & 4.91 \\
\hline Average & Error & & & 612.6 & & 281.9 & & 75.6 & & 17.26 \\
\hline
\end{tabular}

Table 8. Experimental and calculated height using selected equations, B/A/W, h $=39 \mathrm{~cm}$

\begin{tabular}{|c|c|c|c|c|c|c|c|c|c|c|}
\hline $\mathrm{C}_{\text {out }}$ & NTU & Experimental & \multicolumn{2}{|c|}{ Newman } & \multicolumn{2}{|c|}{ Kronig and Brink } & \multicolumn{2}{|c|}{ Handlos and Baron } & \multicolumn{2}{|c|}{ Present Work } \\
\hline [mole/lit] & & {$[\mathrm{m}]$} & $\begin{array}{c}\text { Calculated } \\
{[\mathrm{m}]}\end{array}$ & $\begin{array}{l}\text { Err. } \\
\text { [\%] }\end{array}$ & $\begin{array}{c}\text { Calculated } \\
{[\mathrm{m}]}\end{array}$ & Err. [\%] & $\begin{array}{c}\text { Calculated } \\
{[\mathrm{m}]}\end{array}$ & Err.[\%] & $\begin{array}{c}\text { Calculated } \\
{[\mathrm{m}]}\end{array}$ & Err.[\%] \\
\hline $2.70 \mathrm{E}-05$ & 10.11 & 0.39 & 2.54 & 551.3 & 1.17 & 198.9 & 0.15 & 61 & 0.305 & 21.91 \\
\hline $1.70 \mathrm{E}-05$ & 10.61 & 0.39 & 2.4 & 514.3 & 1.08 & 175.9 & 0.13 & 67.1 & 0.313 & 19.78 \\
\hline 1.90E-04 & 8.19 & 0.39 & 1.99 & 410 & 0.91 & 132.4 & 0.1 & 74.8 & 0.243 & 37.61 \\
\hline $3.10 \mathrm{E}-04$ & 7.7 & 0.39 & 1.86 & 376.2 & 0.85 & 116.7 & 0.08 & 80.1 & 0.239 & 38.77 \\
\hline $1.50 \mathrm{E}-03$ & 6.1 & 0.39 & 3.57 & 815.9 & 1.93 & 395.1 & 0.1 & 73.9 & 0.444 & 13.77 \\
\hline $1.20 \mathrm{E}-03$ & 6.35 & 0.39 & 3.52 & 801.8 & 1.89 & 384.3 & 0.09 & 76.4 & 0.458 & 17.45 \\
\hline $1.80 \mathrm{E}-03$ & 5.93 & 0.39 & 3.24 & 730.4 & 1.74 & 345.1 & 0.08 & 80 & 0.426 & 9.35 \\
\hline $2.70 \mathrm{E}-03$ & 5.54 & 0.39 & 2.95 & 656.5 & 1.58 & 304.2 & 0.07 & 83 & 0.392 & 0.42 \\
\hline $1.30 \mathrm{E}-02$ & 3.96 & 0.39 & 3.73 & 857 & 2.05 & 426.6 & 0.09 & 78.2 & 0.466 & 19.55 \\
\hline $1.60 \mathrm{E}-02$ & 3.76 & 0.39 & 3.64 & 834.2 & 2.01 & 414.9 & 0.07 & 80.9 & 0.444 & 13.84 \\
\hline $1.60 \mathrm{E}-02$ & 3.71 & 0.39 & 3.5 & 797.1 & 1.93 & 394.9 & 0.07 & 82.8 & 0.433 & 11.03 \\
\hline $2.10 \mathrm{E}-02$ & 3.46 & 0.39 & 3.27 & 738.8 & 1.8 & 362.7 & 0.06 & 85.2 & 0.41 & 5.09 \\
\hline \multicolumn{3}{|c|}{ Average Absolute Error } & & 673.6 & & 304.3 & & 76.9 & & 17.38 \\
\hline
\end{tabular}

NTU is 3.89. It means that 3.89 stages are required to reach the desired concentration in the height of 39 $\mathrm{cm}$. Applying the Newman model to predict the mass transfer coefficient and determining the required height of the column using the conventional method leads to $0.73 \mathrm{~m}$ for each stage and totally a column of $2.8 \mathrm{~m}$ is required. However with our proposed approach, 3.89 stages with different heights are needed.i.e. HTU1 = $5.4 \mathrm{~cm}$, HTU2 $=7.7 \mathrm{~cm}$, HTU3 $=8.9 \mathrm{~cm}$ and HTU4 $=9.8 \mathrm{~cm}$. As it was predicted, HTU's are increasing in each experimental run. The corresponding errors for the conventional method applying Newman model and our proposed approach are $627 \%$ and $21 \%$, respectively. The average absolute error of the predicted column height applying proposed correlation for mass transfer coefficient is about $20 \%$. The counterpart values for Newman, Kronig-Brink and Handlos-Baron models are $606 \%, 275 \%$ and $75 \%$, respectively.

\section{CONCLUSION}

In this study mass transfer coefficients is measured experimentally in different heights of packed column to predict its height. The study leads to introduction of a novel conceptual method to predict column height via new correlation for mass transfer coefficient. This new approach is called increasing HTU's. According to the results, the following conclusions are obtained:

- In contrast to previously believed concept, HTU is not a fixed value in column. While the height of column increases the value of HTU increases too.
- The mass transfer coefficient can be obtained with much better precision by applying the effective diffusivity in Newman equation and by introducing the height of the packing in the correlation.

- The experimental results show that the mass transfer coefficient is meaningfully a function of the height of the packing. While the height of packing increases solute concentration decreases and this results in less mass transfer rates.

- Presenting of the mass transfer coefficient as a function of height of packing is a new approach which can provide a theoretical basis for the calculation of column height.

- The conventional method for calculating the column height does not predict the height of column with a satisfactory accuracy while applying the new approach can significantly reduce the average error.

\section{APPENDIX A. NOMENCLATURE}

a $\quad-$ Specific Area

$\mathrm{B}_{\mathrm{n}} \quad$ - Constants of Eqs. (2)\&(3)

c - Solute concentration in dispersed phase $\left(\mathrm{kg} / \mathrm{m}^{3}\right)$

d $\quad-$ Drop diameter (m)

$\mathrm{D}_{\mathrm{d}} \quad-$ Molecular diffusivity $\left(\mathrm{m}^{2} / \mathrm{s}\right)$

$\mathrm{D}_{\text {eff }} \quad-$ Effective diffusivity $\left(\mathrm{m}^{2} / \mathrm{s}\right)$

E - Extraction Efficiency

h $\quad-$ Height of packing (m)

$\mathrm{K}_{\mathrm{d}}-$ - Dispersed phase mass transfer coefficient $(\mathrm{m} / \mathrm{s})$

$\mathrm{K}_{\mathrm{od}}$ - Overall dispersed phase mass transfer coefficient $(\mathrm{m} / \mathrm{s})$

$\mathfrak{R} \quad-$ Enhancement factor for mass transfer 


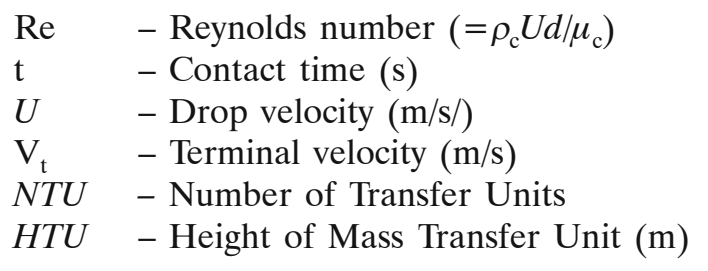

\section{Greek symbols}

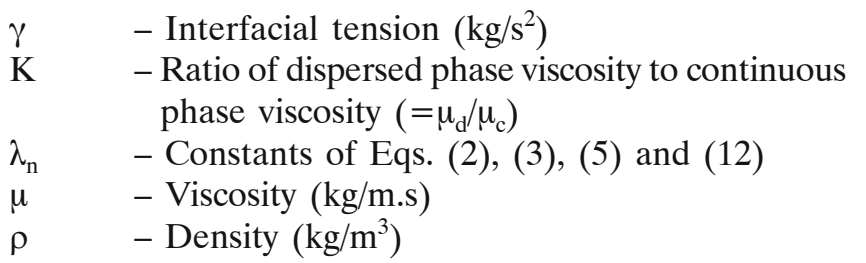

\section{Subscripts}

$\begin{array}{ll}\text { c } & - \text { Continuous phase } \\ \text { d } & - \text { Dispersed phase } \\ 0 & - \text { Initial Drop }\end{array}$

\section{Superscripts}

* $\quad$ - Equilibrium

\section{LITERATURE CITED}

1. Rahbar Kelishami, A., Bahmanyar, H. \& Moosavian, M.A. (2011). Prediction of mass transfer coefficients in regular packed columns, Chem. Eng. Communications 198:8, 1041-1062. DOI: $10.1080 / 00986445.2011 .545305$.

2. Kumar, A. \& Hartland, S. (1999). Correlations for prediction of mass transfer coefficients in single drop systems and liquid-liquid extraction columns, Institution of Chemical Engineers, Trans. IChemE. 77, Part A, 372-384. DOI: $10.1205 / 026387699526359$.

3. Newman, A.B. (1931). The drying of porous solids: Diffusions and surface emission equations, Trans. Am. Inst. Chem. Eng. 27, 203-220.

4. Kronig, R. \& Brink, J.C. (1950). On the theory of extraction from falling drops, Appl. Sci. Res. A2, 142-154. DOI: 10.1007/BF00411978.

5. Handlos, A.E. \& Baron, T. (1957). Mass and heat transfer from drops in liquid-liquid extraction, AIChE J. 3, 127-136. DOI: 10.1002/aic.690030121.

6. Calderbank, P.H. \& Korchinski, I.J.O. (1956) Circulation in liquid drops: a heat transfer study, Chem. Eng. Sci. 6, 65-78. DOI: 10.1016/0009-2509(56)80012-2.

7. Rose, P.M. \& Kintner, R.C. (1966). Mass transfer from large oscillating drops, AIChE J. 12, 530-534. DOI: 10.1002/ aic.690120325.

8. Johnson, A.I. \& Hamielec, A.E. (1960). Mass transfer inside drops, AIChE J. 6 145-149. DOI: 10.1002/aic.690060128.

9. Boyadzhiev, L., Elenkov, D. \& Kyuchukov, G. (1969) On Liquid-Liquid Mass Transfer inside Drops in a Turbulent Flow Field, Can. J. Chem. Eng. 47 42-44. DOI: 10.1002/ cjce. 5450470107 .

10. Steiner, L. (1986). Mass-Transfer Rates from Single Drops and Drop Swarms, Chem. Eng. Sci. 41(8), 1979-1986. DOI: 10.1016/0009-2509.

11. Temos, J., Pratt, H.R.C. \& Stevens, G.W. (1993). Comparison of tracer and bulk mass transfer coefficients for droplets, Proc. ISEC, Elsevier, Amsterdam, 93, 1770-1777. DOI: 10.1016/0009-2509(95)00224-3.

12. Soltanali, S., Ziaie-Shirkolaee, Y., Amoabediny, Gh., Rashedi, H., Sheikhi, A. \& Chamanrokh, P. (2009). Hydrodynamics and mass transfer performance of rotating sieved disc contactors used for reversed micellar extraction of protein, Chem. Eng. Sci. 64, 2301-2306. DOI: 10.1016/j.ces.2009.02.005.
13. Lévêque, J., Rouzineau, D., Prévost, M. \& Meyer, M. (2009). Hydrodynamic and mass transfer efficiency of ceramic foam packing applied to distillation, Chem. Eng. Sci. 64, 2607-2616. DOI: 10.1016/j.ces.2009.02.010.

14. Perry, R.H., Green, D.W. \& Maloney, J.O. (1997) Perrys chemical engineers handbook (7th ed.), NY: McGraw-Hill.

15. Coulson, J.M. \& Richardson, J.F. (1991). Chemical Engineering Vol. 2, 5th ed., p. 639. (Pergamon Press, Oxford.). 